\title{
The Effect of the Difference Between Infographic Designing Types (Static vs Animated) on Developing Visual Learning Designing Skills and Recognition of its Elements and Principles
}

\author{
https://doi.org/10.3991/ijet.v13i09.8541 \\ Mohammed Kamal Afify \\ Imam Abdulrahman Bin Faisal University Dammam, Saudi Arabia \\ mafifyeiau.edu.sa
}

\begin{abstract}
This study aims at studying the effect of the difference between infographic designing types, static versus animated, on developing the skills of designing and producing visual learning materials, and the recognition of the design elements and its principles. The study was conducted on a sample of students of the College of Education at Imam Abdu Rahman bin Faisal University (IAU) in the Kingdom of Saudi Arabia. The number of the sample students is 36 , and they are among the students who are enrolled to study design and production of instructional media course (EDU195N) in the second semester of 2016/2017. The students involved are divided into two experimental groups. Group (1) consisted of 19 students who have studied the learning content through static infographics via WhatsApp platform. And group (2) consisted of 17 students who have studied the learning content through animated infographics via WhatsApp platform. In the overall, the results revealed that infographics effect the development of some learning outcomes. Besides, the results also demonstrated that static infographic type has more effects on developing skills of designing and producing visual learning materials and recognizing its elements and principles compared to the animated type. And this suggests deep consideration of integrating infographics in teaching e-courses, as well as considering the characteristics and appropriateness of each of the designing types, static versus animated when implemented in the instructional processes for better outcomes for learners.
\end{abstract}

Keywords-visual Learning - e-learning Platforms - social networking platform, WhatsApp- computer graphics- principles of visual design- Saudi Arabia

\section{Introduction}

The infographics are modern technologies, which are visual presentations in which graphic drawings (illustrations, symbols, maps, graphics, etc.) are combined with verbal language to transform complex data and concepts into images and drawings that can be clearly and interestingly understood and assimilated. Infographics then are an abridged form of the term "information graphics" that integrates visualization of 
data, illustrations, texts and images all together in a form which is easily understood and assimilated [1], [2].

The infographics are characterized by numerous advantages, including simplifying the scientific facts and presenting them in a visualized data form, shortening explanatory texts, illustrations, and videos to expressive symbols, images and simple denotations, as well as being easier to be produced. In addition, they do not need high-cost software or high programming capabilities. Besides, infographics are widely spread in educational and entertainment social networks, newspapers, magazines, and multiinterest websites more than the other electronic media as well as being less expensive than the other means [3], [4], [5].

The infographics can be designed in more than one type; and perhaps the most prominent ones are static and animated types. The static infographics denote the graphics which are designed for the objective of printed use or digital use in websites, or to be viewed on a screen as digital presentations without integrating any motion, or animated elements or motion properties. As for the animated infographics, they refer to the graphics designed for being displayed on graphic animated video screens on video websites such as YouTube, TV ads or animated presentations on smartphones, etc. The elements and the data in the animated type are in a state of continuous movement; and it is characterized by much creativity in the selection of expressive movements which help to produce the animation in an interesting and enjoyable way. Besides, this type requires a complete scenario to produce the final form using the necessary software programs [6], [7].

Previous research and studies have demonstrated the effectiveness of using infographics in education and the infographics' role in increasing students' success when they are utilized as an alternative to texts. And it was stated that the infographics facilitate learning compared to ordinary texts, as well as enabling learners to participate effectively in the learning process, which results in long lasting learning [8], [9]. As for studies which have compared between the two types of the infographic designing, they concluded with different finding. Some of them have confirmed that static infographics are more effective in achieving some learning outcomes, while other research have demonstrated that animated infographics are more effective in improving some learning outcomes [10], [11], [12], [13], [14]. And this necessitates conducting further research and studies to compare the efficacy of these two types, as the case is in this research.

Infographics are used in e-learning environments which are based on the web through e-learning management systems. They are also used in mobile learning (MLearning) environments through social networking platforms such as WhatsApp, where the learners interact via mobile phones and this makes learning take place anywhere and anytime. The most eminent advantage is that there is no fixed place or need for a specific time to learn. That is to say, adapting learning to the learners' learning styles and to their needs as well as providing opportunities for students to demonstrate their understanding, learning from others besides enriching the teachers with innovative teaching methods [15], [16], [17], [18].

With consideration of the various features of the social networking platform (WhatsApp), this research has used it as a platform for e-learning environment using 
static and animated infographics. Among these features, WhatsApp is considered one of the most widespread and widely used social media platforms among learners. As stated by previous research, social networking platforms have many benefits at the level of students' interaction and in contributing to enhancing the motivation to learn as well as presenting subjects to learners adaptively [19]. In addition to this, they are valuable tools to present the learning activities and to improve students' collaborative skills interestingly. Other studies also have revealed that using social media platforms in teaching has contributed to achieving higher scores by the learners and to bettering the effectiveness with the ability to perform tasks besides acquiring practical skills [20].

\section{The Theoretical Framework}

\subsection{Characteristics of the infographics, theoretical principles, types and educational uses}

Infographics are considered a new way of providing digital learning resources. The innovative aspect of infographics is the usage of visual components in constructing and presenting information [21]. And it can be said that one of the most important features of infographics is their flexible structure which permits the visual portrayal of information, the possibility of preparing them with alternative forms, besides the possibility for using other components in their production, such as video and audio files [1]. Thus, infographics are occupying a spacious place among contemporary learning methods which are based on digital learning sources. The infographics then are characterized by many distinguishable features as follows [1], [22]:

Visual Attractive: The visual attractiveness is considered the essence of infographics use. It combines graphic elements to represent digital data, with an objective textual explanation through icons, images, colors, and all elements and principles of visual designs able to orient the audience and have their attention focused.

Symbolizing and Summarizing: One of the most important features of infographics is the ability to symbolize information, concepts, facts and knowledge into brief presentation in visual symbols, ranging from images, shapes, arrows as well as static and animated graphics.

Ability for Sharing: Infographic designs are produced in the form of digital content, which makes them easy to share across different electronic content platforms, and that enables the readers to learn collaboratively, and supports communication among them. Additionally, their design holds copyrights in high regard so the content is more secure when shared.

Enhancement Ability: The designer can add the links and additional internet addresses as reference for the learners to enrich their culture and knowledge about the subject of infographics. Besides, there is also the possibility for adding the titles of some books, abstracts, studies and related research, which enriches the electronic as well as the printed content. 
Enhancing learning process: Infographics act in having the learning process done in a fast and effective manner. Learners prefer visual images to abstract texts for learning. This can be explained by the fact that infographics constitute an appropriate tool which ensures that students learn important points in the subject matter quickly; and that they attain textual information according to their own speed.

Theoretical principles of infographics: Both types of infographics, static and animated derive their reliability from behavioral theories and approaches whose principles refer to the need for fragmenting the content and information into segments to be processed as very small steps that can be in the form of images, drawings, arrows or static texts. This approach comes in consistency with one of the basic principles of information processing theory. Many studies have shown that learners remember more information and retain them longer when the text is followed by some illustrations or visual aids [23]. According to cognitive load theory (CLT), this phenomenon occurs because the usage of graphics with the text reduces cognitive load, which is the mental effort of the learner in the learning process. Thus, learners can focus more on the content rather than trying to understand the way through which it is presented [24]. Besides, the knowledge acquired from visual images lasts longer. This is because well-prepared visual images have a positive impact on the cognitive learning processes. Students spend less time learning the information presented through infographics because they are less exposed to the cognitive load. Thereby, the positive approach which minimizes the cognitive load is the activities of designing and learning materials which are harmonious with visual information, such as images and graphics, along with textual content in order to save the efforts of learners during the subject assimilation [25].

On the other hand, the gestalt theory as a model of learning by insight adopts the idea which sees that learning consists of the visual recognition of the learning content presented in a complete and unified form and it does not adopt the idea of learning by fragmentation. Thus, this theory tends to align with the animated infographics type based on showing a complete image of the learning content or the processed information in an infographic format linked by one thematic context, unlike the static type which is based on separating information [26].

Types of infographics: There are several types of infographics, namely interactive, semi-interactive (animated) and non-interactive (static). The classification of these types depend mainly on the multimedia components they contain [27]. The static infographics contain texts and non-animated visual components. And the information contained in this type of infographics are confined to the content provided. In addition, this type is used in the printed form. The animated infographics usually contain the same content as in the static type. But there is the ability to see the process or the mentioned data through a single continuous motion, or animated scenes rather than viewed in separate steps or blocks of information. The relatively new animated infographic forms attract more viewers and readers by their unique visual animation characteristics. And the interactive infographics provide the same information as in the two abovementioned types but with multimedia sources, as well as containing the same characteristics of the static infographics [7]. For example, an audio file, video or animated drawings are essential for content in this type of interactive infographics. 
And there are other styles of infographics which belong to this type allowing users to select and access information according to their choices. This feature allows information to be provided as a whole and satisfies the need for additional information.

Educational uses of infographics: The results of many previous studies have demonstrated that the use of infographics in education affects the learners who have different ways of thinking. And they have also demonstrated that infographics provide strong arguments and present them to more than one sensory organ, and help learners to engage effectively in the learning process, resulting in long-lasting learning and higher scores [28]. In addition, infographics contribute to increasing students' success when used as an alternative to texts, facilitating learning compared to ordinary texts [21]. Infographics also help teachers to develop and display learning activities in an appealing way that attracts students' attention, as well as rising awareness towards the subject matter and making it easier to be remembered. This may be thanks to the instructing ability of well-organized visual images which provide a clear message [28]. In parallel with this, the use of infographics in education affects the learning outcomes of learners also [29]. And they are highly effective for teaching complex subjects which involve both quantitative and temporal data which makes them easy to be learned. Besides this, infographics are considered a useful tool for developing some of the students' moral and social values. They can be used to help them assimilate the values presented in the lessons, thus contributing to the development of the learners' personality and providing teachers with new opportunities to identify students' moods and mental states to improve their behavior [30]. Another feature of infographics is taking part in breaking the monotony and boredom for students, resulting from the multitude of verbal presentations. And instead, infographics draw the attention of individuals through visual attractiveness of visual designing elements, which enhances positive orientation towards the learning content [3].

Research in the field of educational technology is concerned with exploring the best ways to design, produce and use learning resources. It is clear from literary reviews that the issue of exploiting the static infographics versus the animated infographics communication and visual learning is not yet resolved and it still needs further studies. And in relation to this issue, this research aims to demonstrate which of the two infographic types, static versus animated, contributes to the improvement of students' learning outcomes.

\subsection{Visual learning designing skills}

Visual learning is one of visual literacy components, which is a medium between visual thinking and visual communication. Visual learning correlates with the ability of the individuals to benefit from what is being presented to them to make the desired internal behavioral changes. Visual learning requires the skill of reading images, and illustrations. The skill of reading images means enabling the learner to observe, describe and interpret the content of the image or the drawing, to extract its concepts, ideas, values, relationships, etc., and to recall these components and their associated words transforming them into spoken or written words [31], [32]. Visual learning also requires two more skills, visual perception and visual production. Visual perception is 
defined as the process of exegesis and interpretation of visual stimuli, giving them meanings and denotations. The visual production skill is defined as the ability to produce a mental image by visual conceptualizations. When the visual forms are seen, recognition takes place and a mental image of the form is made [33].

The process of visual recognition and the factors influencing it form a basic gateway that can be exploited to design educational graphics, in order to facilitate the learner's recognition of the concepts and information transmitted by the image, and to recognize the similarities and the differences between objects and symbols quickly and accurately. Subsequently, developing the visual recognition process and its organizing factors is extremely important for the educational designer. It helps in designing these drawings, helps to produce them and ensures that the message or idea is conveyed through an airtight and good design. The educational designers and the teachers' recognition of the visual design elements on the one hand, and its principles as well as its basics on the other hand, besides the clarification of their core functions in designing and producing digital learning resources is very essential. In that, this recognition is one of the most indispensable outcomes for students of College of Education as teachers and designers of different learning resources. And this is another cause for conducting this research [34].

\section{Problem and Questions of the Research}

In the area of educational technology, learning through infographics has been given a great deal of regard. This is because of its increasing influence as stated by various studies and research. The issue is no longer about the utility of using infographics in e-learning environments, but the most persisting research question is what are the particular designing criteria in learning content designing for educational purposes?

The inconsistencies and the differences in the results of some previous research and studies [6], [10], [11] about the effect of the infographic designing types (static and animated) specifically in the e-learning environments are among our motives to conduct this research. Some studies have indicated that the static infographics are more effective compared to the animated type. On the other hand, other studies have stated that the animated infographics have more effectiveness in achieving some Learning outcomes in contrast to the static type, which confirms the need for further research to help in resolving the issue about which infographic designing type, static or animated, is more effective for improving the learning outcomes.

One of the most important learning outcomes for the students of the College of Education as would-be teachers and designers of different learning materials is the recognition of the designing skills, its elements and its principles on the one hand, and clarifying basic functions of each of them in designing and producing visual digital materials on the other hand. This ultimate need for such recognition forms another reason for conducting this research, which aims at studying the effect of the difference between the infographic designing types - static and animated - on the development of the visual learning designing skills and the recognition of its elements and 
principles among the students of the College of Education. Through this study of the effect of differences, the research aims to answer the following questions:

- Q1 What is the effectiveness of using infographics (static and animated) in the development of: (a) the skills of designing and producing visual learning materials, and (b) the skills of recognizing the elements and principles of visual designing?

- Q2 What is the effect of the difference between infographic designing types (static vs animated) on developing the skills of designing and producing visual learning materials?

- Q3 What is the effect of the difference between infographic designing types (static vs animated) on developing the skills of recognizing the elements and principles of visual designing?

\section{$4 \quad$ Methodology}

\subsection{Research methodology and variables}

In this research, the experimental method has been used to investigate the effect of different infographic designing types - the static and the animated - on developing visual designing skills and the recognition of its elements and principles. The independent variable in the research is the designing type of the learning content through infographics, static versus animated; while the dependent variables are: the skills of designing and producing visual learning materials, and the skills of recognizing the elements and principles of this visual designing.

\subsection{Research sample}

With regard to the research variables and the experimental designing, the research sample consisted of 36 students from the College of Education. The students are studying the design and production of instructional media course (EDUM 195N) in the second semester of 2016/2017, with an average age of 20.09 years and a standard deviation of 1.13. The students are divided into two experimental groups. The first group consists of 17 students who have studied learning content using the static infographics. And the second group consists of 19 students who have studied learning content using the animated infographics.

\subsection{Measurement tools}

The objective of this research is to develop the skills of designing and producing visual learning materials, and to develop skills of recognizing its elements and principles. Therefore, the following measurement tools have been prepared: the observation card to observe students' performance and to observe their skills in designing and producing visual learning materials, and a cognitive test to measure the cognitive aspects for skills of recognizing elements and principles of visual designing. 
The observation card: The objective from the observation card is to measure students' behavioral performance in designing and producing visual learning materials using the necessary computer software programs. And for specifying the measurement aspects for skills of designing visual learning materials, the theoretical approaches and previous studies related to the fundamentals of visual content designing have been reviewed [35], [36], [37], [38] to structure the observation card. This observation card contains the measurement of ten basic skills in the visual production. Each skill includes a set of behavioral performances which the student should implement serially and accurately to obtain the grade of the implementation of behavioral performance, and these skills are: 1 - clarity of the overall goal, the message of the designed visual content, 2 - selecting the design elements which support and firm up the message of the design, 3 - taking focus into consideration as a principle for designing, 4 - degree of balance in the design, 5 - achieving the principle of convergence of similar elements in the design, 6 - taking into consideration the principle of ordering elements, 7 - the principle of contrast between visual elements, 8 - the accuracy of the chosen colors and degrees of color saturation, 9 - the harmony between the used visual elements, 10 - taking spelling and grammatical errors into consideration .

The observation card has been designed to measure the behavioral performance on a four-level scale: 1) the non-proficient level, when the design meets one or none of the skill requirements, and the student's performance is estimated at 2 grades,2) the partially-proficient level in which the designing fulfills more than one skill requirement and it is marked at 4 grades,3) proficient level in which the designing meets most of the skill requirements and it is graded at 6,4) advanced level in which the designing meets all the skill requirements and it is graded 8 . The observation includes 10 basic skills. So, the full score for the performance assessment is 80 which reflect the high performance of the students' skills in designing visual learning materials. The minimum grade is 20 , and it reflects the clumsy or poor performance of the students' designing skills.

For calculating the validity and stability of the observation card, it was presented to a group of specialists in the field of education technology to determine its suitability for the objective of this research, as well as determining accuracy of its formulation and comprehensiveness of the skills represented. The necessary adjustments have been made in the light of the arbitrators' opinions. Besides, this observation card has been applied by the researcher when evaluating the productions of the sample of the survey study who had studied this course before, apart from the basic sample of this research. The intrinsic validity of the observation card has been calculated through computing the matrix of correlation coefficients between its dimensions and the total score. The correlation coefficients ranged from 0.431 to 0.857 , which are statistically the function value of 0.01 , indicating the consistency of the internal structure of the observation card. For calculating the stability of the observation card, the researcher has observed the performance of the survey study sample and then evaluated their productions. Then, two other colleagues observed the performance of the same sample and the stability was calculated through Cooper equation to compute the ratio of the agreement and the difference between the observers. The ratio of agreement 
ranged between $87.2 \%$ and $94.7 \%$ which indicated the stability of the observation card.

Preparation of the cognitive test: The test was designed and prepared for the purpose of measuring the degree to which the students of the College of Education recognize the elements and principles of visual design which are necessary for the production of visual learning materials. The previous literature [35], [36], [37], [38] has been used as reference to structure the vocabulary of the test in an objective manner such as multiple choice questions. The objective is to measure the cognitive aspects according to Bloom's classification of "understanding, application, analysis, composition, and evaluation". The test has covered the elements of visual design (space, line, shape, fabric) as well as its principles (unity, order, balance, repetition, point of focus, harmony, and other principles). The vocabulary of the test was based on the visual vocabulary to clarify how to answer the questions. The test consisted of 50 paragraphs as the final form. In order to grade answers, the correct answer was graded 1, while wrong answer was graded 0 . The test was answered and answers have been corrected and graded electronically using QuizCreator program, one of the etests programs. The full test score for the 50 paragraphs is 50 grades.

The validity of the content or the structure credibility of the test was confirmed through presenting it to a group of arbitrators from the teaching board members of the specialty. They were asked to provide their feedback and comments about the formulation of questions and on the linguistic correctness, the question appropriateness to the target it measures, and the coverage of questions for all the elements of visual designing and the basics of visual learning materials designing as well as the scientific accuracy of its formulation, and the appropriateness of paragraphs' number in the test. The researcher as well has calculated the intrinsic validity of the test by calculating the matrix of correlation coefficients between the test terms and the total score in the test. The correlation coefficients ranged from 0.386 to 0.847 which are statistically function value of 0.01 indicating the consistency of the internal structure of the cognitive test. Besides, the researcher has calculated the stability of the test through applying it to the survey sample of the study after they have completed studying the same content. The test stability was calculated using the alpha-Cronbach stability coefficient scale; the stability coefficient value was equal to 0.92 , which is sufficient for the objective of this research. The difficulty and discrimination coefficients have been calculated also for the test paragraphs. And it was required to re-form Four paragraphs because their discrimination coefficient was less than 0.20 . Thus, the final test consisted of 50 paragraphs fit to be used for the objective of this research.

\subsection{Design and development of the research experiment}

The process of designing and developing electronic content has passed through systematic and organized steps. In order to achieve the objective of this research, the researcher has designed two experiential experiments for the learning content through the two infographics' types. The first one is to present the learning content in the form of static infographics. And the second one is to present the learning content in the form of animated infographics. Both experiments were conducted via the mobile 
learning platform, WhatsApp. The researcher designed the experimental experiment and developed it by using (ADDIE) model. The ADDIE model is a systematic instructional design model consisting of five phases: (1) Analysis, (2) Design, (3) Development, (4) Implementation, and (5) Evaluation [39].

Analysis phase: the following steps were taken:

Setting the objective of the experiential experiment: There is a need to investigate the effect of the different types of infographic designing - static versus animated - on developing the skills of visual learning design and on recognizing its elements and principles among the students of the College of Education. And this is the overall purpose of developing the experiment material.

Determining the characteristics of the targeted learners: The learners are students from the College of Education who are enrolled to study the course "Design and Production of instructional media (EDUM 195N)". The course is supposed to enable the students with the necessary knowledge and skills to produce visual learning resources. And since the teacher or the educational designer's recognition of visual designing elements on the one hand, and the principles of visual designing on the other, as well as clarifying their core functions in designing, and since producing digital learning resources is very essential as an indispensable outcome for students of the college of Education as teachers and designers of different learning sources, we have suggested designing the experiential experiment for this research.

Analysis of educational tasks: The educational tasks were pinpointed in skills of designing and producing visual learning materials, as well as in the skills of recognizing visual designing elements and its principles. These tasks require prior expertise and practical skills in computer usage, computer file management systems, electronic text writing, digital multimedia production skills and different computer visuals such as Publisher, PowerPoint, Photoshop, and Edrawmax. And the researcher has made sure that the research sample are versed in these skills as a prerequisite requirement before the implementation of the research experiment.

Design phase: the following steps were taken:

Formulation of educational objectives: The objective of the experiential experiment was to provide the students with the following learning outcomes: a) determining the elements of visual design and its principles necessary for producing visual learning materials, b) demonstrating knowledge about the elements and the principles of visual design through visual learning and communication processes, c) acquiring the skills of designing and producing visual learning materials in accordance with the principles of visual design and its standards, d) identifying examples of visual designing elements and its principles - for learning productions - in other students' work (peer assessment), e) translating the understanding of visual design elements and its principles into practical design and production of visual learning materials.

Specifying the content structure of learning: In the light of the learning outcomes of the course (EDU195N), the learning content of the experimental material has been pinpointed in the following topics: visual literacy, visual thinking, visual learning, visual communication, visual design elements, principles of design, visual perception and factors affecting it, human memory and information processing, and infographics. 
Specifying the criteria for the infographic design, static versus animated: The researcher has considered the criteria of designing the learning content in the form of infographics types, static and animated, when designing the experiential experiment of the research. The criteria are as follows:

The criteria for the subject: The key criteria in relation to the subject are: simplicity and conciseness in presenting information, systematic presentation of information and data using punctuation to facilitate memorizing information and recall them when needed, focus on one subject to be addressed by infographics, the criterion of sequenced information display and organization, the search for information sources that are reliable, accurate and clear, and the criterion of benefit and assimilation. Besides this, due concern was given to the criterion of providing communication through infographics effectively and knowledge that allows clear understanding of information. Also, the information must be meaningful and well organized and comparable as well as having the appropriate flow. And there was also consideration of retention. That is to say, communicating through infographics must be of memorable knowledge that is unforgettable and the visual infographic design should target the optic receptors in the human brain that process data and information and cement them in longterm memory. Finally, the criterion of correctness of spelling and accuracy of grammar was also taken into consideration [40].

Design criteria: For the design, criteria of attractiveness and beauty have been considered as follows: the infographic visual design must attract the attention of the target audience and indulge them deeper in the presentation. The design also must have an aesthetic appeal that attracts the viewer's attention and offers a pleasant visual experience. Besides, the criterion of visual persuasion was considered. In that the message to be communicated must be expressed effectively through using attractive colors related to the subject of infographics, which would result in real and honest changes through affecting the psyche and behavior of the recipient [7], [40].

Learning activities and tasks design: The achievement of research objectives has required designing the learning activities and tasks as follows: activity 1 : designing an educational poster about one of the topics of the student's choice, activity 2: designing a visual educational board about one of the topics of student's choice, activity 3: summarizing one of the learning topics contained in the book of social studies for the fifth grade of the primary school and producing it in the form of graphs, activity 4: designing an electronic presentation for an educational lesson. These activities should be done in accordance with the requirements. The criteria of the static design of visual learning materials which are: The design should be done effectively according to visual design elements and principles. The design should have visual impact on the viewer and the production should have the ability to grab attention, transmitting a clear learning message to the target audience. The design should have a clear title and subtitles to support the message of the content. The production should be readable and proofread for spelling mistakes. The design should be in acceptable formats for electronic files (png, jpg, pdf). The design should consider print quality and should be printable in different sizes (A4, A0). The design should use original or copyright-free images. 
Experiential experiment design processes: Two experiential experiments were designed for the learning content through infographics. The first experiment was designed to present the learning content in the form of static infographic type. And the second experiment was designed to present the learning content in the form of animated infographic type. As for the platform which was employed, WhatsApp platform was used to display the content of e-learning through infographics in its two types, static and animated.

Development phase: The two experiential experiments have produced the learning content of the infographic types, static and animated, as follows:

The first experiment: The content of learning was produced in the form of static infographics in the light of the criteria of the infographic design referred to in the previous phase using "Adobe Illustrator", one of the programs produced by Adobe. This program is considered the best for designers in the production of artistic designs and infographic designing, thanks to the magnificence of its designing options, ultimate flexibility, and its ability to produce attractive results. It also depends on vector drawing instead of pixels, which does not affect the drawings in any way when they are made larger in size or smaller or by any other changes. This allows the designer to apply industry-specific drawings in the field to design logos, icons, drawings, lines and complex illustrations for printing and for interactive web, as well as videos and mobile phone pictures. The experiment has resulted in 30 static infographics which covered all the elements of the educational content in the experiment subject.

The second experiment: The learning content was produced in the form of animated infographics in the light of the infographics criteria referred to in the previous sections using After Effects, a video editing program. This program is used in the digital video industry, films, special effects and fiction effects, television productions, motion graphic animation, animations, and visual effects. It also allows designers to move or change video in two-dimensions $2 \mathrm{D}$ and 3D with various merging tools and add-ons in the program. This program is also used by most animated infographic designers for its flexibility and its great features in the field of visual animation designing. The experiment resulted in 30 animated infographics with a duration of 1 to 2 minutes for each, covering all elements of the educational content of the experiment.

Application phase: This phase represents the actual use of the experiential experiment material by the research sample according to the following procedural steps:

- Disseminating the learning content of the static infographics on the mobile elearning platform, WhatsApp.

- The researcher divided the sample of the research into students of group (1) to study the learning content using static infographics, and to interact with it via WhatsApp platform, and students of group (2) to study the learning content using animated infographics and to interact with it through the WhatsApp platform.

- Content access control was made available through WhatsApp platform, by creating a contact group for this purpose, and by adding phone numbers of all students in the group.

- In the first meeting, the professor of the course has outlined the time plan face-toface with students for studying the course, the way of implementing the learning 
activities, evaluation methods used, e-content of the course and how to learn it through the e-learning platform, as well as specifying the learning tasks to be carried out by the learners.

- The students have carried out the practical assignments and tasks required from them, namely designing and producing of learning activities, as described in the section of designing the experiential experiment using the necessary computer software. After the period specified for the delivery of the assignments has finished, students submitted them electronically to the professor of the course to evaluate and grade them.

- The experiment implementation lasted for eight weeks starting from the third week until the eleventh week of the second semester of the academic year 2016/2017.

Evaluation phase: This phase reveals the effect of achieving the experiment's objectives. And this was done through: a) exploratory study, a survey was conducted on a sample of learners to express their opinions about the elements of the content prepared via the two infographic types, static and animated, and the way to present them through the M-learning platform (WhatsApp), b) exploring experts' opinions: opinions of some academic experts specialized in the field of educational and communication technology were explored to express their remarks about the content and how to build and develop it, besides stating their views about the extent to which the infographic designing criteria were respected, as well as the appropriateness of content to research objective and its achievement of learning outcomes for learners. The required modifications were made based on the previous revisions, so that the experimental materials in their final version are valid for use in this study.

\section{$5 \quad$ Research Results}

5.1 Answer to Q1: What is the effectiveness of using infographic (static and animated) in the development of: (a) the skills of designing and producing visual learning materials, and (b) the skills of recognizing the elements and principles of visual designing?

Arithmetic averages, standard deviations and significance of differences between the students' scores in the pre and post-test measurement scores for the students' performance on the observation card and the cognitive test. The differences significance between the averages were then calculated using paired- samples T-Test. And the results are shown in table 1 .

The results shown in table 1 demonstrate the existence of statistically significant differences at the level of (0.01) between the mean scores of the pre- and post-test scores of the students of the two experimental groups in their performance for the skills of designing and producing visual learning materials on the observation card; and they also demonstrate the difference in their performance in the cognitive tests for recognizing the elements and the principles of visual design. These differences in preand post-test scores denote the effectiveness of the use of both the static and the animated infographics on developing the skills of recognizing the elements and the prin- 
ciples of visual design, as well as the skills of designing and producing visual learning materials.

Table 1. The significance of the differences between the pre - posttest measurement scores for the students' performance on (observation card and the cognitive test)

\begin{tabular}{|c|c|c|c|c|c|c|c|c|}
\hline \multirow{2}{*}{$\begin{array}{l}\text { Dependent } \\
\text { variables }\end{array}$} & \multirow{2}{*}{$\begin{array}{c}\text { infographic } \\
\text { designing types }\end{array}$} & \multicolumn{2}{|c|}{ Pretest } & \multicolumn{2}{|c|}{ Posttest } & \multirow{2}{*}{ df } & \multirow{2}{*}{$\mathbf{t}$} & \multirow{2}{*}{ Sig. } \\
\hline & & Mean & $S D$ & Mean & $S D$ & & & \\
\hline \multirow{2}{*}{$\begin{array}{l}\text { Cognitive } \\
\text { Test }=50\end{array}$} & Static, $N=17$ & 22.06 & 5.09 & 47.35 & 1.86 & 16 & 18.48 & 0.000 \\
\hline & Animated, $\mathrm{N}=19$ & 19.26 & 5.50 & 40.11 & 1.85 & 18 & 15.83 & 0.000 \\
\hline \multirow{2}{*}{ Skills Test $=70$} & Static, $\mathrm{N}=17$ & 27.41 & 4.4 & 75.18 & 2.48 & 16 & 39.23 & 0.000 \\
\hline & Animated, $\mathrm{N}=19$ & 24.21 & 3.83 & 72.37 & 2.65 & 18 & 44.06 & 0.000 \\
\hline
\end{tabular}

5.2 Answer to Q2: "What is the effect of the difference between infographic designing types (static vs animated) on the development of designing and producing visual learning materials skills?"

Arithmetic averages, standard deviations and significance of differences between the students' scores in the two experimental groups were calculated on the observation card based on their performance in designing and producing visual learning materials. The differences significance between the averages were then calculated using independent sample T-Test. And the results are shown in table 2.

Table 2. The differences between the scores of the experimental groups in the postmeasurement of designing and producing visual learning materials skills

\begin{tabular}{|l|c|c|c|c|c|c|c|}
\hline \multirow{2}{*}{$\begin{array}{c}\text { Dependent } \\
\text { variable }\end{array}$} & \multicolumn{2}{|c|}{ Static, N=17 } & \multicolumn{2}{c|}{ Animated, N=19 } & \multirow{2}{*}{ df } & \multirow{2}{*}{ T } & \multirow{2}{*}{ Sig } \\
\cline { 2 - 5 } & Mean & SD & Mean & SD & & \\
\hline $\begin{array}{l}\text { Skills of designing and } \\
\text { producing visual learning } \\
\text { materials=70 }\end{array}$ & 75.24 & 0.53 & 71.37 & 2.65 & 34 & 3.32 & 0.019 \\
\hline
\end{tabular}

The results presented in table 2 show that there was a statistically significant function value difference of level $(0.05)$ between the scores of the two experimental groups who have interacted with the infographics learning content types, static versus animated through WhatsApp platform in their performance for the skills of designing and producing visual learning materials on the observation card. The difference was in favor of students who interacted with the learning content in the form of static infographics with an arithmetic mean of (75.24) and a standard deviation of (2.53), against an arithmetic mean of (71.37) with a standard deviation of (2.65) for students who interacted with the learning content in the form of animated infographics. And that states that there was an effect of the static infographic designing type in favor of the group that used the learning content through the static infographic type. 


\subsection{Answer to Q3: "What is the effect of the difference between infographic designing types (static vs animated) on developing the skills of recognizing the elements and principles of visual design?"}

Arithmetic averages, standard deviations and significance of differences between the students' scores in the two experimental groups were calculated on the observation card based on their performance in the cognitive test of recognizing the elements and principles of visual design. Then, the differences between the averages have been calculated using independent samples T-Test. And the results are shown in table 3.

Table 3. The differences between the scores of the experimental groups in the postmeasurement of recognizing the elements and principles of visual design.

\begin{tabular}{|l|c|c|c|c|c|c|c|}
\hline \multirow{2}{*}{\begin{tabular}{c}
\multirow{2}{*}{$\begin{array}{c}\text { Dependent } \\
\text { variable }\end{array}$} \\
\cline { 2 - 6 }
\end{tabular}} & \multicolumn{2}{|c|}{ Static, $\mathbf{N}=\mathbf{1 7}$} & \multicolumn{2}{c|}{ Animated, $\mathbf{N}=\mathbf{1 9}$} & \multirow{2}{*}{ df } & \multirow{2}{*}{ T } & \multirow{2}{*}{ Sig } \\
\hline $\begin{array}{l}\text { Cognitive } \\
\text { Test }=50\end{array}$ & 47.35 & 1.86 & 1.86 & 2.65 & 34 & 11.6 & 0.024 \\
\hline
\end{tabular}

The results presented in table 3 show that there was a statistically significant function value difference of 0.01 between the scores of the two experimental groups who have interacted with the infographics learning content types, static versus animated through WhatsApp platform in their performance in the cognitive test for recognizing the elements and principles of visual design. The difference was in favor of students who interacted with the learning content in the form of static infographics with an arithmetic mean of (47.35) and a standard deviation of (1.86) against an arithmetic mean of (40.11) and a standard deviation of (1.85) for students who interacted with the learning content in the form of animated infographics. And that states that there was an effect of the static infographic designing type in favor of the group that used the learning content through the static infographic type.

\section{Discussion}

The results of this study have stated that the use of both static and animated infographics is effective in developing the skills of recognizing the elements and principles of visual design, as well as the skills of designing and producing visual learning materials. And this can be explained as follows: The use of infographics is characterized by many distinctive merits. Visual attractiveness is considered the essence of infographics use. Also, the ability to symbolize information, concepts, facts and knowledge to brief presentation in visual symbols, ranging from images, shapes, arrows and static and animated graphics make using the infographics positively influential in achieving satisfactory learning outcomes . Besides, elements and principles of visual designs are able to orient the audience and have their attention focused. Also, the infographics act in enhancing learning process; in that learners prefer visual images with less cognitive load to abstract texts for learning. This is because infographics constitute an appropriate tool which ensures that students learn important points in the 
subject matter quickly, and that they attain textual information according to their own speed. All of this evoke the attractiveness towards infographics leading to the development of skills of designing and producing visual learning materials, as well as recognizing the elements and principles of visual design. And these results came in consistency with the results of some previous research [5], [8], [9].

Besides, the results of this study have stated that there were statistically significant differences between the average scores of the experimental group of the students who interacted with the learning content in the form of static infographics, and the average scores of the students in the group that interacted with the learning content in the form of animated infographics in their performance of: a) skills of designing and producing visual learning materials, b) skills of recognizing the elements and principles of visual design. The difference was in favor of the students who interacted with learning content in the form of static infographics. And this can be explained as follows:

In the light of static infographics characteristics, where information in visual texts and components are static, the information are limited to the content provided, and easy to interact with, besides display zooming in/out control; while the animated infographics present the same content, but through one continuous motion or animated scenes rather than separate steps or blocks of information.

Another possible explanation is that the static infographics provided the students with the needed flexibility to navigate the entire infographic subject visually, as one unity back and forth, getting all the information provided at the same time, and enabling learners to read the text and display the information simultaneously until they have understood the subject completely at every stage or segment of the infographics. Besides, the static infographics help learners to learn the conceptual processes, and to discover relationships more easily within the same infographics, thus improving their learning outcomes. On the other hand, the animated infographics seems to provide learners with a lot of data, but it prevents their minds from making their own logic. And according to the cognitive load theory (CLT), the use of static infographics with the text reduces the learner's cognitive load during the learning process, so learners can focus more on content rather than trying to understand how it is presented [24]. Conversely, the learning process becomes increasingly difficult with the excessive amount of information provided through different tools using multiple media and components, diverse capabilities and a large amount of information that should be addressed [11].

The results of this study are consistent with the results of similar studies reviewed by Mayer et al. (2005) [11] about the efficiency of learning through animated graphics versus static graphics. They found that some of these studies have not provided consistent proof that the animated infographics are better than static type. In that, the animated graphics include much data and information more than the static graphics. These results as well coincide with what have been stated about the unproven superiority of animated graphics in providing an easier way to understand complex subjects [12]. In a study by Peters (2013) [10], It was found that when learning complex cognitive tasks and processes, the motion provides learners with more than what they need. And the motion hinders the learners' minds from decoding relationships which can be easily found in static images, where they can see and read at their own 
pace. Thereby, he concluded that learning of conceptual processes would be more effective through static forms.

\section{Conclusions}

The results of this study have revealed that the difference in the infographic designing types has effects on the skills of designing and producing visual learning materials, and on the skills of recognizing the visual design elements and its principles in favor of students who have interacted with the learning content in the form of static infographics. The static infographic design type has enabled symbolizing information, concepts, facts, and knowledge to brief presentation through picture symbols, ranging from images, shapes, arrows, and graphics. Besides, infographic designing in the form of digital content, made it easy to be shared across the social networking platform, WhatsApp; and that allows the readers to learn collaboratively and to support communication between them [3]. Additionally, the use of the visually attractive static infographics, which combine graphic elements to represent digital data with objective textual explanations using icons, images, colors, and all graphic design elements and principles, has guided students and focused their attention on the subject they are learning.

In the light of these results, this research recommends integrating the infographic technology in the teaching of electronic courses to create an educational environment that attracts the attention of learners and increases learning opportunities as well as retention of information for a long time.

The study also recommends taking into consideration the quality of visual design elements and actualizing its standards and principles in all electronic educational presentations for the students of the College of Education, to develop the artistic and aesthetic aspect which will contribute to the development of their performance in designing and producing visual educational materials as designers and producers of printed and digital sources of learning. In addition, it is recommended to use the MLearning environment, especially through the social networking platform, WhatsApp, as it provides effective tools that act in transmitting the learning resources to learners directly, as well as providing opportunities to interact in a collaborative manner. The study also suggests conducting further research to compare the effect of different types of infographics and their transmitting methods in improving the learning outcomes, the effect of the interaction between the patterns of the infographic design, the cognitive styles of the learners, and studying the patterns of presenting infographics across different e-learning platforms, and its impact on improving learning outcomes for learners.

\section{$8 \quad$ References}

[1] Krum, R. (2013). Cool Infographics: Effective Communication with Data Visualization and Design. John Wiley \& Sons. NJ. USA 
Paper-The Effect of the Difference Between Infographic Designing Types (Static vs Animated) on ...

[2] Meirelles, I. (2013). Design for Information: An Introduction to the Histories, Theories, and Best Practices Behind Effective Information Visualizations. Rockport Publishers.

[3] Matrix, S., \& Hodson, J. (2014). Teaching with infographics: Practicing new digital competencies and visual literacies. Journal of Pedagogic Development, 4(2), 17-27.

[4] Smiciklas, M. (2012). The power of infographics: Using pictures to communicate and connect with your audiences. Que Publishing.

[5] Vanichvasin, P. (2013). Enhancing the quality of learning through the use of infographics as visual communication tool and learning tool. Proceedings ICQA 2013 International Conference on QA Culture: Cooperation or Competition http://www.icqa2014.com/downloads/Proceeding_29.pdf\#page=135 (Access Date: 19.01.2015).

[6] Hassan, H. G. (2016). Designing Infographics to support teaching complex science subject: A comparison between static and animated Infographics (Doctoral dissertation, IOWA STATE UNIVERSITY).

[7] Lankow, J., Ritchie, J., \& Crooks, R. (2012). Infographics: The power of visual storytelling. John Wiley \& Sons. NJ. USA.

[8] Schrock, K. (2014). Infographics as a creative assessment. Retrieved September 29, 2014, from http://www.schrockguide.net/infographics-as-an-assessment.html

[9] Borkin, M. A., Vo, A. A., Bylinskii, Z., Isola, P., Sunkavalli, S., Oliva, A., \& Pfister, H. (2013). What makes a visualization memorable? IEEE Transactions On Visualization And Computer Graphics, 12(19), 2306-2315. https://doi.org/10.1109/TVCG.2013.234

[10] Peters, D. (2013). Interface design for learning: Design strategies for learning experiences. Pearson Education.

[11] Mayer, R. E., Hegarty, M., Mayer, S., \& Campbell, J. (2005). When static media promote active learning: annotated illustrations versus narrated animations in multimedia instruction. Journal of Experimental Psychology Applied, 11(4), 256. https://doi.org/10.1037/ 1076-898X.11.4.256

[12] Lievemaa, J. (2017). Animated Infographics in Digital Educational Publishing: Case Study of Educational Animated Infographics.

[13] Locoro, A., Cabitza, F., Actis-Grosso, R., \& Batini, C. (2017). Static and interactive infographics in daily tasks: A value-in-use and quality of interaction user study. Computers in Human Behavior, 71, 240-257 https://doi.org/10.1016/j.chb.2017.01.032

[14] Ozdamli, F., \& Ozdal, H. (2018). Developing an Instructional Design for the Design of Infographics and the Evaluation of Infographic Usage in Teaching Based on Teacher and Student Opinions. Eurasia Journal of Mathematics, Science and Technology Education, 14(4), 1197-1219

[15] Sahrir, M. S., Zainuddin, N., \& Nasir, M. S. (2016). Learning Preference among Arabic Language Learners via Mobile Learning Management System Platform (Mobile LMS) Using I-Taleem. International Journal of Current Research in Life Sciences, 5(01), 509-514.

[16] Barhoumi, C. (2015). The Effectiveness of WhatsApp Mobile Learning Activities Guided by Activity Theory on Students' Knowledge Management. Contemporary Educational Technology, 6(3), 221-238.

[17] Wang, Y., Tang, S., \& Zhou, Y. (2012, April). A preliminary study on instructional design model in M-learning. In Consumer Electronics, Communications and Networks (CECNet), 2012 2nd International Conference on (pp. 3070-3073). IEEE.

[18] Tay, E., \& Allen, M. (2011). Designing social media into university learning: Technology of collaboration or collaboration for technology? Educational Media International, 48(3), 151-163. https://doi.org/10.1080/09523987.2011.607319 
Paper-The Effect of the Difference Between Infographic Designing Types (Static vs Animated) on ...

[19] Racthman, P., \& Firpo, D. (2011). Using social networking technology to enhance learning in higher education: A case study using Facebook. Paper presented at the 44th Hawaii International Conference on Systems Sciences Hawaii, USA.

[20] Tower, M., Latimer, S., \& Hewitt, J. (2014). Social networking as a learning tool: Nursing students' perception of efficacy. Nurse education today, 34(6), 1012-1017. https://doi.org/10.1016/j.nedt.2013.11.006

[21] Dick, M. (2014). Interactive infographics and news values. Digital Journalism, 2(4), 490506. https://doi.org/10.1080/21670811.2013.841368

[22] Davis, M., \& Quinn, D. (2013). Visualizing text: The new literacy of infographics. Reading today, 31(3), 16-18.

[23] Majooni, A., Masood, M., \& Akhavan, A. (2017). An eye-tracking study on the effect of infographic structures on viewer's comprehension and cognitive load. Information Visualization, 1473871617701971.

[24] Sweller, J. (2017). The role of independent measures of load in cognitive load theory. In Cognitive Load Measurement and Application (pp. 17-22). Routledge.

[25] Ricker, T. J., \& Cowan, N. (2017). Cognitive load as a measure of capture of the focus of attention. Cognitive Load Measurement and Application: A Theoretical Framework for Meaningful Research and Practice

[26] Mahmoudi, M. T., Mojtahedi, S., \& Shams, S. (2017). AR-based value-added visualization of infographic for enhancing learning performance. Computer Applications in Engineering Education, 25(6), 1038-1052. https://doi.org/10.1002/cae.21853

[27] Yildirim, S. (2017). Approaches of designers in the developed educational purpose of infographics of infographics' design processes. European Journal of Education Studies.

[28] Lee, E. J., \& Kim, Y. W. (2016). Effects of infographics on news elaboration, acquisition, and evaluation: Prior knowledge and issue involvement as moderators. New media \& society, 18(8), 1579-1598. https://doi.org/10.1177/1461444814567982

[29] Çifçi, T. (2016). Effects of Infographics on Students Achievement and Attitude towards Geography Lessons. Journal of Education and Learning, 5(1), 154. https://doi.org/10.5539/jel.v5n1p154

[30] İslamoğlu, H., Ay, O., İliç, U., Mercimek, B., Dönmez, P., Kuzu, A., \& Odabaşı, F. (2015). Infographics: A new competency area for teacher candidates. Cypriot Journal of Educational Sciences, 10(1), 32-39.

[31] Buhl, M. (2017, October). Students and Teachers as Developers of Visual Learning Designs with Augmented Reality for Visual Arts Education. In European Conference on eLearning (pp. 94-100). Academic Conferences International Limited.

[32] Agostinho, S., Harper, B., Oliver, R., Hedberg, J., \& Wills, S. (2008). A visual learning design representation to facilitate dissemination and reuse of innovative pedagogical strategies in university teaching. In Handbook of visual languages for instructional design: Theories and practices (pp. 380-393). IGI Global. https://doi.org/10.4018/978-1-59904729-4.ch019

[33] Agostinho, S. (2011). The use of a visual learning design representation to support the design process of teaching in higher education. Australasian Journal of Educational Technology, 27(6). https://doi.org/10.14742/ajet.923

[34] Bylinskii, Z., Kim, N. W., O'Donovan, P., Alsheikh, S., Madan, S., Pfister, H., ... \& Hertzmann, A. (2017, October). Learning visual importance for graphic designs and data visualizations. In Proceedings of the 30th Annual ACM Symposium on User Interface Software and Technology (pp. 57-69). ACM. https://doi.org/10.1145/3126594.3126653

[35] Pedwell, R. K., Hardy, J. A., \& Rowland, S. L. (2017). Effective visual design and communication practices for research posters: Exemplars based on the theory and practice of 
Paper-The Effect of the Difference Between Infographic Designing Types (Static vs Animated) on ...

multimedia learning and rhetoric. Biochemistry and Molecular Biology Education, 45(3), 249-261. https://doi.org/10.1002/bmb.21034

[36] Bestley, R., \& Noble, I. (2016). Visual Research: An Introduction to Research Methods in Graphic Design. Bloomsbury Publishing.

[37] Collins, W., Hass, A., Jeffery, K., Martin, A., Medeiros, R., \& Tomljanovic, S. (2015). Graphic Design and Print Production Fundamentals. BCcampus, BC Open Textbook Project.

[38] Kimball, M. A. (2013). Visual design principles: An empirical study of design lore. Journal of Technical Writing and Communication, 43(1), 3-41. https://doi.org/10.2190/TW.43.1.b

[39] Branch, R. M. (2009). Instruction design: The ADDIE approach (Vol. 722). Springer Science \& Business Media. https://doi.org/10.1007/978-0-387-09506-6

[40] Taguchi, K., \& Ackerman, L. (2014, October). The Infographic: Is there a Place in Higher Education? In E-Learn: World Conference on E-Learning in Corporate, Government, Healthcare, and Higher Education (pp. 1901-1905). Association for the Advancement of Computing in Education (AACE).

\section{$9 \quad$ Author}

Mohammed Kamal Afify is an associate professor of educational technology in college of education at Imam Abdulrahman Bin Faisal University, Saudi Arabia. He has authored a numerous articles in the field and published extensively in different areas. His research interests vary from applying educational technology in higher education to quality standards and implementations in eLearning environments. Address: Department of Educational Technology, College of Education, Imam Abdulrahman Bin Faisal University, P. O. Box 1982, Dammam, 31441, Saudi Arabia.

Article submitted 10 March 2018. Resubmitted 19 April 2018. Final acceptance 04 May 2018. Final version published as submitted by the author. 